Journal of

Dentistry and Oral Health

\title{
Effect of Antioxidants on Shear Bond Strength of Ceramic Veneers to Office Bleached Enamel
}

\author{
Amal Suleiman Al-Awdah ${ }^{1}$, Wedad Yassin Awliya ${ }^{2 *}$ \\ ${ }^{1}$ Lecturer, Department of Restorative Dental Sciences, college of Dentistry/ King Saud University, Riyadh, Kingdom \\ of Saudi Arabia \\ ${ }^{2}$ Professor and consultant, Department of Restorative Dental Sciences, College of Dentistry/ King Saud University, \\ Riyadh, Kingdom of Saudi Arabia
}

${ }^{*}$ Corresponding author: Wedad Y. Awliya, Professor and consultant Department of Restorative Dental Science, college of Dentistry, King Saud University, Riyadh, Saudi Arabia, Tel: 00996505294516; E-mail: wawliya@hotmail.com

Received Date: August 22, 2018; Accepted Date: September 25, 2018; Published Date: September 27, 2018

Citation: Amal Suleiman Al-Awdah (2018) Effect of Antioxidants on Shear Bond Strength of Ceramic Veneers to Office

Bleached Enamel. J Dent Oral Health 5: 1-8.

\section{Abstract}

Purpose: Several studies confirmed the effectiveness of antioxidants in reversing the compromised bond strength of composite resin bonded immediately after bleaching enamel with $10 \%$ carbamide peroxide. This study aimed to investigate the effect of two different antioxidants surface treatments on shear bond strength of ceramic veneers bonded to enamel immediately after $25 \%$ hydrogen peroxide office bleaching.

Materials and Methods: 35 sounds freshly extracted human third molars were used, utilizing both buccal and lingual enamel surfaces for bonding. The samples were randomly divided into seven groups $(\mathrm{n}=10)$. The enamel surfaces were bleached with $25 \%$ hydrogen peroxide except the last group (control) which was bonded to enamel without bleaching. In group 1, enamel bonding was performed immediately after bleaching. In groups 2-5, enamel surfaces were treated immediately after bleaching with either sodium ascorbate or $\alpha$-Tocopherol solutions in two concentrations (10 and 25\%) prior to bonding. while in group 6; bonding was delayed for two weeks after immersion in artificial saliva. Specimens were subjected to shear bond strength test at cross-head speed of $0.5 \mathrm{~mm} / \mathrm{min}$. The fracture analysis was observed using stereomicroscope. Results were analyzed using one-way analysis of variance (ANOVA) and Tukey tests at a significant level of $\mathrm{P}=0.05$.

Results: ceramic veneers bonded immediately to enamel treated with both concentrations of sodium ascorbate showed higher shear bond strength than veneers bonded to enamel treated with $\alpha$-Tocopherol solutions. However, no significant difference was detected between the two antioxidants. Enamel treatments with both antioxidants following bleaching showed no significant difference in the bond strength than the bonding immediately after bleaching.

Conclusion: Delayed bonding to enamel after office bleaching still the best method to reverse the compromised bond strength.

Keywords: bleaching, antioxidant, sodium ascorbate, $\alpha$-Tocopherol, Ceramic veneer, Shear bond strength 


\section{Introduction}

Many clinicians consider vital tooth bleaching as the first treatment option in severely discolored teeth because it is the most conservative approach. However, there is a high possibility of a negative influence of this procedure on any further dental treatments such as bonding to the tooth structure. The reduction in the bond strength of the adhesive restorations bonded to enamel immediately after tooth bleaching has been stated in many studies [1-3].

Some techniques have been suggested to enhance the bond strength of previously bleached teeth such as removing the superficial layer of enamel or treating the bleached enamel surface with alcohol before bonding the restoration $[1,4,5]$. However, delaying the bonding procedure for a period of time is considered the best solution, since the reduction of bond strength has been shown to be reversible [6-10]. Lai et al introduced the use of an antioxidant (sodium ascorbate) as a surface treatment which can immediately reverse the compromised bond strength of bleached teeth with hydrogen peroxide or teeth treated with sodium hypochlorite [3]. Many studies confirmed the effectiveness of $10 \%$ sodium ascorbate in reversing the compromised bond strength of previously bleached enamel with $10 \%$ carbamide peroxide and bonded to resin composite [11-13]. In 2009, Sasaki et al found that another antioxidant, which is a-tocopherol, was highly effective in reversing the compromised bond strength after bleaching [14]. Most of the studies mentioned previously examined the effect of antioxidants on shear bond strength of enamel to composite resin or ceramic veneers following home bleaching (10\% carbamide peroxide) [11-13]. The objective of this study was; to investigate the effect of two percentages of sodium ascorbate (vitamin C) and $\alpha$-Tocopherol antioxidant (vitamin E) enamel surface treatments on the shear bond strength of ceramic veneers bonded to office bleached enamel (25\% hydrogen peroxide).

\section{Materials and Methods}

Thirty-five sounds human third molars were used in this study. They were free of caries, cracks, abrasion facets, fluorosis, and damage from extraction. Following extraction, teeth were washed thoroughly and stored in distilled water with $0.05 \%$ thymol solution. The roots were removed approximately $2 \mathrm{~mm}$ below the cemento-enamel junction using a slow-speed diamond saw (Isomet 2000, Buehler, Lake Buff, Illinois, USA) under a water-coolant spray. The crown of each tooth was then sectioned in the mesio-distal direction in order to use both the buccal and lingual enamel surfaces for the bonding procedures. Self-cure acrylic resin (Ortho resin, Dentsply, UK) was loaded in polyvinyl chloride (PVC) cylindrical molds which was fabricated and used for mounting the teeth. Each sectioned specimen either buccal or lingual surface was embedded in the acrylic resin while it was soft so that the buccal or lingual surfaces facing upwards for the bonding procedure. The embedded enamel surfaces were grounded and polished using 240-, 400-, 600-grit silicon carbide paper (Buehler, Lake Bluff, Illinois, USA) to create a uniform flat, polished surface that is flushed with the acrylic resin. This step also aids in grinding the enamel surface to be ready for the bonding procedure. The samples were inspected with light microscope (Steeozoom 5, Bausch \& Lomp, USA) to ensure that the enamel surface was intact and no dentin was exposed. Then, the samples were randomly divided into seven groups $(n=10)$, as shown in (Table 1$)$.

\section{Preparation of the Ceramic Samples}

Seventy discs of a lithium disilicate glass-ceramic, shade A1, (IPS e.max Press, LT A1, Ivoclar Vivadent, Liechtenstein) were fabricated using a circular custom-made stainless-steel mold with a thickness of $0.7 \mathrm{~mm}$ and width of $3 \mathrm{~mm}$ using lost wax and heat pressed techniques. The discs were ultrasonically cleaned for $15 \mathrm{~min}$ in ethanol and deionized water then randomly divided into the tested groups.

\section{Preparation of the Antioxidants}

Sodium ascorbate and $\alpha$-Tocopherol solutions were prepared as described by Sasaki et al [14] in two concentrations as shown in Table 2. The materials for

Preparing the solutions were obtained from Sigma-Aldrich ${ }^{\odot}$ Chemical Company/England.

\section{Bleaching Procedure}

Enamel specimens in groups 1-6 were bleached with 25\% hydrogen peroxide (Zoom Advanced, Discus Dental) as the manufacturer instructions. Five samples, only from each group, were bleached in each bleaching session to ensure the complete light coverage on the samples. Each sample completed four sessions of 15 minutes each, giving a total of one-hour office bleaching. After the bleaching procedure, all specimens were washed with distilled water and placed in a labeled container with fresh distilled water.

\section{Application of Antioxidant}

After bleaching, all specimens in the test groups from 2-6 were subjected to treatment with antioxidant solutions. The assigned antioxidant solution was applied onto the surface of each enamel specimen for 10 minutes as the methodology of Turkun et al [15].

\section{Bonding Procedure}

The surfaces of the ceramic discs that bonded to the tooth structure were etched with $4.9 \%$ hydrofluoric acids (IPS ceramic etching gel, Ivoclar, Schaan, Liechtenstein) for 60 seconds. Then, silane (Monobond-S, Ivoclar, Schaan, Liechtenstein) was applied using a micro brush on the ceramic surface and left to react for 60 seconds and dried gently with a stream of air.

Before bonding, a piece of adhesive tape was punched with a circular, $3 \mathrm{~mm}$ in diameter. The hole was securely adapted to the center of the flattened portion of the enamel to limit the 
Table1: Groups used in the study

\begin{tabular}{|l|l|l|l|}
\hline Groups & $\begin{array}{l}\text { Bleaching } \\
\text { Treatment }\end{array}$ & Antioxidant Treatment & Bonding \\
\hline 1 & $25 \%$ HP & None & Immediately after bleaching \\
\hline 2 & $25 \%$ HP & $10 \%$ SAS & After Treatment \\
\hline 3 & $25 \%$ HP & $25 \%$ SAS & After Treatment \\
\hline 4 & $25 \%$ HP & $10 \%$ ATS & After Treatment \\
\hline 5 & $25 \%$ HP & $25 \%$ ATS & After two weeks immersion in artificial saliva \\
\hline 6 & $25 \%$ HP & None & After two weeks immersion in artificial saliva \\
\hline 7 & None & None & \\
\hline
\end{tabular}

* HP: Hydrogen peroxide. SAS: Sodium ascorbate solution. ATS: $a$-tocopherol solution

Table 2: Antioxidants Surface Treatment

\begin{tabular}{|l|l|l|l|}
\hline Groups & Treatment Agent & Composition & PH \\
\hline 2 & $10 \%$ sodium ascorbate solution & $\begin{array}{l}\text { sodium ascorbate and } \\
\text { water }\end{array}$ & 8 \\
\hline 3 & $25 \%$ sodium ascorbate solution & $\begin{array}{l}\text { sodium ascorbate and } \\
\text { water }\end{array}$ & 8 \\
\hline 4 & $10 \%$ a-Tocopherol solution & $\begin{array}{l}\alpha \text {-Tocopherol and alcohol } \\
\text { a-Tocopherol and alcohol }\end{array}$ & 5.5 \\
\hline 5 & $25 \%$-Tocopherol solution & -Ton & \\
\hline
\end{tabular}

bonding surface. The demarcated enamel surface was etched with phosphoric acid 37\% (etching gel, Ivoclar, Schaan, Liechtenstein) for 30 seconds, washed and dried. The totaletch adhesive system (Syntac ${ }^{\oplus}$, Ivoclar Vivadent, Schaan, Liechtenstein) was applied according to the manufacturers' instructions. Syntac ${ }^{\otimes}$ Primer was applied to the enamel surface with a disposable tip brush provided by the system kit for 15 seconds then dried gently. Then, Syntac ${ }^{\oplus}$ Adhesive was applied to the enamel surface with a new brush for 10 seconds and dried gently as a second layer. After that both the enamel and the ceramic surfaces were ready to apply the hydrophobic adhesive (Heliobond, Ivoclar Vivadent, Schaan, Liechtenstein) which was applied by a disposable brush then dried gently.

A customized stainless-steel mold was fabricated with thickness of $0.5 \mathrm{~mm}$ to stabilize the ceramic veneer disc. A $3 \mathrm{~mm}$ circular hole was made in the center of this mold, the same size as the ceramic disc. The mold was placed in the center of the punched area of the enamel surface so that the two holes (on the mold and the treated enamel surface) were in intimate contact. The peripheries of the PVC were stabilized with the mold using wax. Variolink ${ }^{\circledR}$ Veneer (Ivoclar Vivadent, Schaan, Liechtenstein) was placed in the mold hole followed by the treated ceramic disc. The excess cement was removed with a disposable micro-brush. A thin glass slap with a length of $75 \mathrm{~mm}$, width of $25 \mathrm{~mm}$ and thickness of
$1 \mathrm{~mm}$ was placed on the top of the ceramic disc and stabilized with a static constant load (weight of 200 grams) in each side of the slap. The ceramic discs were light cured vertically for 40 seconds according to the manufacturer instructions with a halogen previously calibrated light curing device (Elipar ${ }^{\text {тм }} 2500$ Halogen Curing Light, $3 \mathrm{M}^{\mathrm{TM}} \mathrm{ESPE}^{\mathrm{TM}}$ ), then the glass slap and mold were gently removed and the light was circumferentially rotated until the total time of curing was 120 seconds. The excess of resin cement was removed with a scalpel blade.

After bonding, the samples were stored in distilled water at $37^{\circ} \mathrm{C}$ for at least 24 hours then subjected to 1000 cycles in thermocycling apparatus (Thermocycler THE1100/1200, SD Mechatronik) between bathes of 5 and $55^{\circ} \mathrm{C}$ with a dwell time of 30 seconds. The specimens in groups six and seven were immersed in $250 \mathrm{ml}$ of artificial saliva at $37^{\circ} \mathrm{C}$ for two weeks. Artificial saliva was prepared as described by Cavalli et al [9].

\section{Shear Bond Strength Testing and Mode of Bond Failure}

The specimens were subjected to a shear bond strength test using a universal testing machine (Instron 8500, England) with a load cell of $10 \mathrm{KN}$. A knife edge rod with a width of $0.5 \mathrm{~mm}$ was applied at the interface of the ceramic veneer disc with the enamel at cross-head speed of $0.5 \mathrm{~mm} / \mathrm{min}$. 
The fracture sites along the enamel-ceramic disc interface were observed under the stereomicroscope (Stereo 80 Widefield Microscope, Swift, CA, USA) to determine the modes of bond failure. Fracture modes were classified as adhesive, cohesive or mixed and were defined as follows: adhesive failure showed no sign of enamel fracture or remnants of ceramic on the tooth. Cohesive fractures showed complete fracture of enamel or resin, while mixed samples showed both adhesive and cohesive failures.

One-way analysis of variance (ANOVA) was used to compare the mean values across the seven groups, followed by Tukey HSD to compare among the seven groups. A p-value of $<0.05$ was considered as statistically significant.

\section{Results}

The mean shear bond strength for all experimental groups is presented in (Table 3 ) and expressed in (Figure 1).

There was no significant difference between delaying bonding for two weeks after bleaching and bonding without any bleaching procedure $(\mathrm{P}=0.999)$. Bleached enamel immersed in saliva for two weeks before bonding showed significantly higher bond strength to ceramic veneers than enamel surfaces bonded immediately after bleaching without antioxidant surface treatment $(\mathrm{P}=0.000)$. ceramic veneers bonded immediately to enamel treated with both concentrations of sodium ascorbate showed higher shear bond strength than veneers bonded to enamel treated with $\alpha$-Tocopherol solutions. However, no significant difference was recorded between the two antioxidants (Table 4). Also, ceramic veneers bonded to beached enamel surfaces treated with both antioxidants at the different concentrations, showed significantly lower shear bond strength than ceramic veneers bonded to the delayed bonded group.

The distribution of failure across the seven groups was given in a (Table 5). From the Table, it was noticed that most the adhesive failures in this study were at the ceramic/resin cement interface.

\section{Discussion}

The bonding of ceramic veneers immediately after enamel bleaching in the present study showed significantly reduced bond strength than when the veneers bonded to unbleached enamel. This result was stated in many similar previous studies [16-19]. The bleaching agents release free radicals as nascent oxygen and hydroxyl or peri-hydroxyl ions when they are applied to the dental structure [19]. These free radicals may interfere with the resin infiltration into the etched enamel or inhibit the polymerization of the resin [20-23]. Changes in proteins and in mineral content of most superficial layers of enamel after bleaching may also responsible for the reduction in bond strength [23].

The results of the present study showed that there were no significant differences between the shear bond strength of veneers bonded to unbleached enamel and those delayed bonding for two weeks after bleaching. This might be explained by the possible morphological or structural repair in bleached enamel during the waiting period before bonding while teeth were restored in artificial saliva $[9,11]$. Several studies found no significant difference between using an antioxidant surface treatment immediately after bleaching procedure and delaying the restorative bonding for at least two weeks [14,24,25]. These studies explained their findings to the use of sodium ascorbate which allows free-radical polymerization of the adhesive resin to proceed without premature termination by restoring the altered redox potential of the oxidized bonding substrate, thus reversing the compromised bonding [3]. Since Vitamin $\mathrm{C}$ and its salts are non-toxic and are widely used in the food industry as antioxidants, it is unlikely that their intraoral use will create any adverse biological effect or clinical hazard [11]. However, the result of this study showed no significant difference between treating the enamel with antioxidant and the immediate bonding after dental bleaching. This could be attributed to the difference in concentration of bleaching agents used in this study and the other studies. It was found that hydrogen peroxide produces more morphological changes and more loss of calcium and phosphorus in enamel than carbamide peroxide. This might reflect on enamel bond strength [26].

Although treating enamel surfaces after bleaching with $10 \%$ sodium ascorbate in this study did not produce significant higher bond strength to resin cement than other treatment modalities, it recorded the highest bond strength among the antioxidant groups. Shear bond strength gained in this study after enamel treatment with $10 \%$ Sodium ascorbate (23.01 $\mathrm{MPa}$ ) was within the acceptable range reported in the literature (between 16 and $24 \mathrm{MPa}$ ), partially exceeding the cohesive strength of enamel [ 27,28]. Using sodium ascorbate after bleaching might be promising in cases where bonding has to be performed immediately to ensure better bond strength than bonding immediately without any surface treatment. This recommendation is also supported by the mode of failure as seen by the stereomicroscope. The ascorbic acid-treated specimens both concentrations showed a $100 \%$ adhesive failure between the resin cement and the ceramic 
Table 3: Mean, Standard Deviation and Standard Error of Shear Bond Strength of Bleached Enamel to Ceramic Veneers

\begin{tabular}{|c|c|c|c|c|c|c|c|c|c|}
\hline \multicolumn{2}{|c|}{ Groups } & \multirow{2}{*}{$\begin{array}{l}\mathbf{N} \\
\\
10\end{array}$} & \multirow{2}{*}{$\begin{array}{l}\text { Mean } \\
18.44\end{array}$} & \multirow{2}{*}{$\begin{array}{l}\text { SD } \\
4.25\end{array}$} & \multirow{2}{*}{$\begin{array}{l}\text { Std. } \\
\text { Error } \\
1.34\end{array}$} & \multicolumn{2}{|c|}{$\begin{array}{l}95 \% \text { Confidence Interval for } \\
\text { Mean }\end{array}$} & \multirow{2}{*}{$\begin{array}{l}\text { Min } \\
11.52\end{array}$} & \multirow{2}{*}{$\begin{array}{l}\text { Max } \\
26.17\end{array}$} \\
\hline (1) & $\operatorname{Im} B$ & & & & & 15.40 & 21.47 & & \\
\hline (2) & $10 \%$ SAS & 10 & 23.01 & 5.19 & 1.64 & 19.30 & 26.73 & 17.06 & 33.30 \\
\hline (3) & $25 \%$ SAS & 10 & 21.97 & 5.96 & 1.88 & 17.71 & 26.23 & 16.53 & 35.79 \\
\hline (4) & $10 \%$ ATS & 10 & 18.25 & 4.61 & 1.46 & 14.95 & 21.55 & 11.12 & 28.00 \\
\hline (5) & $25 \%$ ATS & 10 & 16.83 & 4.06 & 1.28 & 13.93 & 19.73 & 12.09 & 24.34 \\
\hline (6) & Del B & 10 & 31.86 & 7.86 & 2.49 & 26.24 & 37.49 & 17.78 & 41.58 \\
\hline (7) & No Bl & 10 & 33.18 & 9.78 & 3.09 & 26.19 & 40.18 & 21.62 & 49.24 \\
\hline & Total & 70 & 23.36 & 8.61 & 1.03 & 21.31 & 25.42 & 11.12 & 49.24 \\
\hline
\end{tabular}

${ }^{\star}$ Im B: Immediate bonding after bleaching procedure; SAS: Sodium ascorbate solution antioxidant surface treatment; ATS: AlfaTocopherol solution antioxidant surface treatment; Del B: Delayed bonding procedure for two weeks after bleaching; No Bl: Bonding to enamel without bleaching.

Table 4: Post Hoc Tests (Tukey HSD- multiple range tests) Showing the Means in Homogenous Subsets

\begin{tabular}{|l|l|l|}
\hline \multirow{2}{*}{ Group } & \multicolumn{2}{|l|}{ Subset for $\alpha=0.05$} \\
\cline { 2 - 3 } & 1 & 2 \\
\hline 5 & 16.83 & \\
\hline 4 & 18.25 & \\
\hline 1 & 18.44 & \\
\hline 3 & 21.97 & \\
\hline 2 & 23.01 & \\
\hline 6 & & 31.86 \\
\hline 7 & & 33.18 \\
\hline Sig. & .308 & .999 \\
\hline
\end{tabular}

*group 1: Immediate bonding after bleaching procedure; group2:10\% Sodium ascorbate solution antioxidant surface treatment; group3: 25\% Sodium ascorbate solution antioxidant surface treatment. group4:10\% Alfa-Tocopherol solution antioxidant surface treatment. group5:25\% Alfa-Tocopherol solution antioxidant surface treatment; group6:

Delayed bonding procedure for two weeks after bleaching; group7: Bonding to enamel without bleaching. 
Figure 1: Mean Shear Bond Strength Values of the Different Tested Groups.

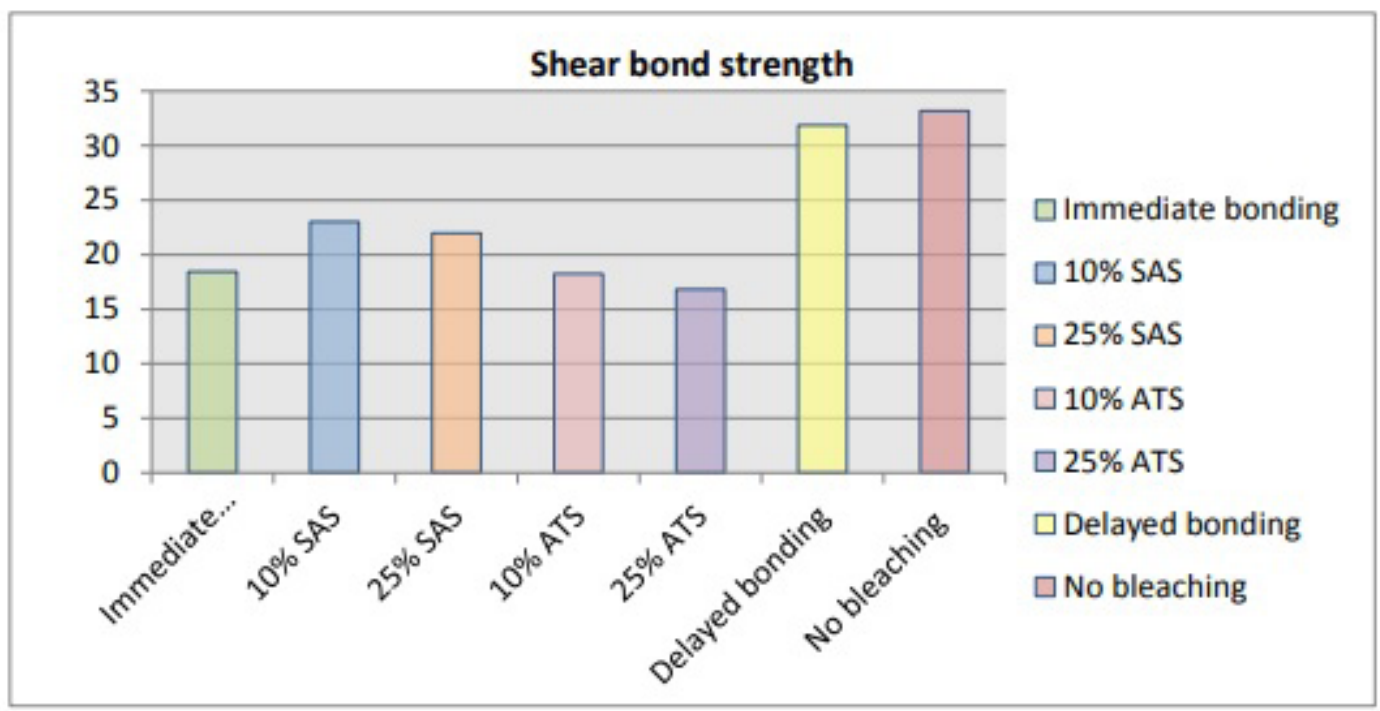

Table 5: Mode of Fracture of the Different Test Groups

\begin{tabular}{|c|c|c|c|c|c|c|c|c|c|}
\hline \multicolumn{2}{|c|}{ Mode of Failure } & \multicolumn{7}{|l|}{ Group } & \multirow{3}{*}{$\begin{array}{l}\text { Total } \\
78.6 \%\end{array}$} \\
\hline & & 1 & 2 & 3 & 4 & 5 & 6 & 7 & \\
\hline Adhesive & \% within Group & $70.0 \%$ & $100.0 \%$ & $100.0 \%$ & $60.0 \%$ & $60.0 \%$ & $90.0 \%$ & $70.0 \%$ & \\
\hline Cohesive & $\%$ within Group & $.0 \%$ & $.0 \%$ & $.0 \%$ & $10.0 \%$ & $10.0 \%$ & $10.0 \%$ & $.0 \%$ & $4.3 \%$ \\
\hline Mixed & \% within Group & $30.0 \%$ & $.0 \%$ & $.0 \%$ & $30.0 \%$ & $30.0 \%$ & $.0 \%$ & $30.0 \%$ & $17.1 \%$ \\
\hline Total & $\%$ within Group & $100.0 \%$ & $100.0 \%$ & $100.0 \%$ & $100.0 \%$ & $100.0 \%$ & $100.0 \%$ & $100.0 \%$ & $100.0 \%$ \\
\hline
\end{tabular}

*group 1: Immediate bonding after bleaching procedure; group2:10\% Sodium ascorbate solution antioxidant surface treatment; group3: 25\% Sodium ascorbate solution antioxidant surface treatment. group4:10\% Alfa-Tocopherol solution antioxidant surface treatment. group5:25\% Alfa-Tocopherol solution antioxidant surface treatment; group6: Delayed bonding procedure for two weeks after bleaching; group7: Bonding to enamel without bleaching. 
disc with the enamel surface was completely covered with the resin cement. As a result, the oxidation reducing effect by the ascorbic acid treatment was validated. An ascorbic acid solution has an etching potential and highly acidic which may enhance the micromechanical retention of the resin. In other words, ascorbic acid was effective in maintaining the bond strength of the resin material not only by reducing the residual oxygen, but also by etching the tooth surface [19].

Although Sasaki et al claimed that $\alpha$-Tocopherol antioxidant was effective in reversing the compromised bond strength of resin cement to enamel after bleaching, this was not the case in this study [14]. Ceramic veneers bonded to enamel surfaces treated with $\alpha$-Tocopherol showed the least values of SBS in comparison with other groups in the study. This might be attributed to its physical properties; it has semi-viscous texture which may interfere with its complete wettability to the enamel surface [29]. Thus, this might affect its ability to remove the free oxygen radicals from enamel. Farther investigation is needed; increasing the application time might contribute to its ability to reverse the compromised bond strength after bleaching.

\section{Conclusions}

Within the limitation of this in-vitro study, the following conclusion was drawn:

1. Bonding ceramic veneers immediately after enamel bleaching with $25 \%$ hydrogen peroxide showed significantly lower bond strength than bonding veneers to unbleached enamel.

2. The compromised bond strength of ceramic veneers to enamel, bleached with $25 \%$ hydrogen peroxide was reversible, after two weeks immersion of enamel in saliva before bonding.

3. There was no significant difference between bleached enamel surfaces wither treated with any antioxidant or bonded immediately after bleaching without treatment.

4. Among all the antioxidants used in this study, $10 \%$ sodium ascorbate showed high shear bond strength values which might be a promising material in reversing the reduced bond strength after enamel vital bleaching.

\section{Acknowledgments}

Special thanks to King Abdulaziz City for Science and Technology in Riyadh/Saudi Arabia for sponsoring this research

\section{References}

1) Cvitko E, Denehy G, Swift E, Pires J (1991) Bond strength of composite resin to enamel bleached with carbamide peroxide. J Esthet Dent 3:100-102.

2) García-Godoy F, Dodge W, Donohue M, O'Quinn J (1993) Composite resin bond strength after enamel bleaching. Oper Dent 18:144-147.

3) Lai S, Mak Y, Cheung G, Osorio R, Toledano M, et al (2001) Reversal of compromised bonding to oxidized etched dentin. J Dent Res 80: 1919-1924.

4) Barghi N. Godwin J (1994) Reducing the adverse effect of bleaching on composite-enamel bond. J Esthet Dent 6:157-161.

5) Sung E, Chan S, Mito R, Caputo A (1999) Effect of carbamide peroxide bleaching on the shear bond strength of composite to dental bonding agent enhanced enamel. J Prosthet Dent 82:595-599.

6) McGuckin R, Thurmond B, Osovitz S (1992) Enamel shear bond strengths after vital bleaching. Am J Dent 5:216222 .

7) Dishman M, Covey D, Baughan L (1994) The effects of peroxide bleaching on composite to enamel bond strength. Dent Mater 10: 33-36.

8) Ben-Amar A, Liberman R, Gorfil C, Bernstein Y (1995) Effect of mouthguard bleaching on enamel surface. Am J Dent 8:29-32.

9) Cavalli V, Reis A, Giannini M, Ambrosano G (2001) The effect of elapsed time following bleaching on enamel bond strength of resin composite. Oper Dent 26:597-602.

10) Uysal T, Basciftci F, Uşümez S, Sari Z, Buyukerkmen A (2003) Can previously bleached teeth be bonded safely? Am J Orthod Dentofacial Orthop 123:628-632.

11) Lai S, Tay F, Cheung G, Mak Y, Carvalho R et al (2002) Reversal of compromised bonding in bleached enamel. J Dent Res 81: 477-481.

12) Turkun M. Kaya A (2004) Effect of $10 \%$ sodium ascorbate on the shear bond strength of composite resin to bleached bovine enamel. J Oral Rehabi 31:1184-1191.

13) Bulut H, Turkun M, Kaya A (2006) Effect of an antioxidizing agent on the shear bond strength of brackets bonded to bleached human enamel. Am J Orthod Dentofacial Orthop 129:266-272.

14) Sasaki R, Flório F, Basting R (2009) Effect of 10\% sodium ascorbate and 10\% alpha-tocopherol in different formulations on the shear bond strength of enamel and dentin submitted to a home-use bleaching treatment. Oper Dent 34:746-752. 
15) Turkun M, Arici M (2009) Can the hydrogel form of sodium ascorbate be used to reverse compromised bond strength after bleaching? J Adhes Dent 11: 35-40.

16) Gökçe B, Cömlekoğlu M, Ozpinar B, Türkün M, Kaya A (2008) Effect of antioxidant treatment on bond strength of a luting resin to bleached enamel. J Dent 36:780-785.

17) Kimyai S, Valizadeh H (2006) The effect of hydrogel and solution of sodium ascorbate on bond strength in bleached enamel. Oper Dent 31: 496-499.

18) Muraguchi K, Shigenobu S, Suzuki S, Tanaka T (2007) Improvement of bonding to bleached bovine tooth surfaces by ascorbic acid treatment. Dent Mater J 26: 875-881.

19) Kaya A, Türkün M, Arici M (2008) Reversal of compromised bonding in bleached enamel using antioxidant gel. Oper Dent 33:441-447.

20) Titley K, Torneck C, Smith D, Adibfar A (1988) Adhesion of composite resin to bleached and unbleached bovine enamel. J Dent Res 67: 1523-1528.

21) Titley K, Torneck C, Smith D, Chernecky R, Adibfar A (1991) Scanning electron microscopy observations on the penetration and structure of resin tags in bleached and unbleached bovine enamel. J Endod 17: 72-75.

22) Murchison D, Charlton D, Moore B (1992) Carbamide peroxide bleaching: effects on enamel surface hardness and bonding. Oper Dent 17:181-185.

23) Perdigão J, Francci C, Swift E Jr, Ambrose W, Lopes M (1998) Ultra-morphological study of the interaction of dental adhesives with carbamide peroxide-bleached enamel. Am J Dent 11: 291-301.

24) Kaya A, Turkun M (2003) Reversal of dentin bonding to bleached teeth. Oper Dent 28: 825-829.

25) Bulut H, Kaya A, Turkun M (2005) Tensile bond strength of brackets after antioxidant treatment on bleached teeth. Eur J Orthod 27: 466-471.

26) Llena C, Esteve I, Forner L (2017) Effect of Hydrogen and Carbamide Peroxide in Bleaching, Enamel Morphology, and Mineral Composition: In vitro Study. J Contemp Dent Pract 18:576-582

27) Barkmeier W, Cooley R (1992) Laboratory evaluation of adhesive systems. Oper Dent 5: 50-61.

28) Krämer N, Lohbauer U, Frankenberger R (2000) Adhesive luting of indirect restorations. Am J Dent 13: 60D-76D.

29) Engin KN (2009) Alpha-tocopherol: looking beyond an antioxidant. Mol Vis.15: 855-860.

\section{Submit your manuscript to a JScholar journal} and benefit from:

ฯ Convenient online submission

ब Rigorous peer review

- Immediate publication on acceptance

ๆ Open access: articles freely available online

ब High visibility within the field

I Better discount for your subsequent articles Submit your manuscript at

http://www.jscholaronline.org/submit-manuscript.php 